\title{
M00Cs of Inclusive Technology in Teacher Education for Vocational Education
}

\author{
Rosana Wagner ${ }^{1,2}$, Sandra Piovesan1, Liliana Passerino1, José Valdeni De Lima1, \\ Carlos De Castro Lozano² \\ ${ }^{1}$ Programa de Pós Graduação em Informática na Educação, Universidade Federal do Rio Grande do Sul, \\ Porto Alegre, Brasil \\ ${ }^{2}$ Centro de Produção e Experimentação de Conteúdos Digitais de Rede, Universidad de Córdoba, \\ Córdoba, España \\ Email: rosanawagner@gmail.com, sanpiovesan@gmail.com, Ipasserino@gmail.com, valdeni@inf.ufrgs.br, \\ carlos@uco.es
}

Received 21 August 2015; accepted 9 October 2015; published 13 October 2015

Copyright (C) 2015 by authors and Scientific Research Publishing Inc.

This work is licensed under the Creative Commons Attribution International License (CC BY). http://creativecommons.org/licenses/by/4.0/

(c) (i) Open Access

\section{Abstract}

Technology is a strong ally the transformation and adaptation of new knowledge, through the use of technology environments as virtual learning environments and virtual reality environments can be made more dynamic learning. This work is part of the training of teachers who work in vocational courses so that they can work with people with disabilities and insert them into the labor market, adapting their job according to your needs. For this we used technological resources that assist in training and make this more dynamic training, adapting to Massive Open Online Course (MOOCs). The technological environment developed as well as the selected learning objects were made available to participants. Questionnaires regarding usability and functionality were performed, allowing to generate an overview of the training provided to these teachers.

\section{Keywords}

Teacher Training, MOOCs, Vocational Education, Assistive Technology, People with Disabilities, Distance Education

\section{Introduction}

The quality of education is the great challenge linked to the current generation. Brazil is experiencing a moment of development, occupying the 7th place in the world economy, pointing increasingly towards a professional qualification to enter the world of work (Pronatec, 2013). Given this reality, there is the urgent need to train 
skilled professionals to work in a globalized and increasingly demanding market.

The teachers who work in the formation of Young Apprentice and PRONATEC mostly do not have teacher training. Most teachers are technical areas and do not have adequate training to work in a classroom where there is diversity. You can see a need for continuing education for teachers of technical areas can meet the demands of the classroom.

Some laws were created with the intention of assisting the inclusion and integration of people with disabilities in the labor market. Law No. 8112 of December 11, 1990, in its second article, ensures that persons with disabilities not only the right to enroll in public procurement, whose duties are compatible with their disability but also ensures the reservation of up to twenty percent of the positions offered in the tender for these people.

Another policy highlight is the Law 8213 of 1991, called "Quota Law". Since then, the government's action has sought to safeguard the right to work of disabled people through the enforcement of the said law (Brasil, 2004).

However, there is a need for proposals enabling achieve de facto equality of opportunity between disabled workers and other workers. For this, you can start by vocational education. It is necessary to provide, at all levels of education, educational tools oportunizem different ways of learning meet the different needs in an inclusive perspective.

On the other hand, the training of human resources, especially in the case of vocational education, has often found it difficult, especially towards inclusion of people with disabilities in policies such as vocational education. The main difficulty often still comes from within the classroom, where there are no teachers with specific training to deal with diversity in the classroom.

Faced with this panorama in relation to teacher training and educational practices has aimed this proposed structure a MOOC technology that aids in the formation of the Professional Education teachers in order to qualify them for inclusion of disabled people in the market of work.

The technological change implies deep alterations on the comprehension of social interaction processes and in the learning and knowledge building (Stiubiener, 2011). The Distance Education (DE) is a teaching modality that increases every day. Nowadays the DE is based on the TICs and facilitated and improved through the static Virtual Learning Environments (VLE) like the Moodle, Wikispaces, Google Course Builder, Teleduc and the Eduquito. In consonance with the $\mathrm{DE}$ and the search for information made a new concept to emerge, the MOOCs. The use of dynamic environments and learning objects multimodal on these contexts, they help minimizing the distance among the students involving them much more with the course.

Online education has been constantly reshaping the concept of distance learning. Currently integrate the concept of MOOCS. MOOCs are free, open to anyone, and designed to handle an extremely large number of students. You might think that MOOCs would cover only esoteric subjects offered by obscure schools, but that's not the case (Machun, 2012).

Based on this context, created the SolAssist Learning. The SolAssist Learning is a subproject that makes up the SolAssist (Assistive Solutions Library) the TEIAS group (Technology in Education Inclusion and Learning Society), of UFRGS.

The SolAssist Learning aims to qualify professionals working in the vocational education and people with disabilities, enabling them to use assistive technology resources, assisting in the professional qualification of persons with disabilities, as well as the adaptation of jobs for inclusion of these people in the working world.

\section{Vocational Education}

In Brazil, vocational education is to support the industry in strengthening its sustainable development and social responsibility, providing opportunities that actions in favor of inclusion and diversity are performed. Training Courses Initial and Continuing are offered to the community with the goal of training skilled manpower for industries.

Some of the key skill programs currently in Brazil are Pronatec (National Program for Access to Technical Education and Employment) and the Young Apprentice. The Pronatec-National Program for Access to Technical Education and Employment proposed by the Ministry of Education, is run by the Federal Institutes and the system S (Pronatec, 2013). The nice Apprentice is a learning program focused on the preparation and insertion of young people in the world of work, which is based on Law 10,097/2000, the Law of Learning (Aprendiz Legal, 2014). Its objective is to enable companies to invest in an apprentice who, after conducting their training, 
can be hired as an employee, including for disabled quota that companies must meet

Currently teachers who work in Pronatec e courses and Young Apprentice mostly do not have teacher training, and are not prepared to work in a classroom where there is diversity.

\section{Teacher Training}

Although early experiences in inclusion have been made in the second half of the 80s, was in the early 90s that the world of education took note of a new path to a quality school and truly open to all people (Sassaki, 2005).

This way, known as inclusive education, differs substantially from the old forms of school integration of people with disabilities and/or other atypical conditions, in the sense that the inclusion requires changes in perspective from which education should be understood (Sassaki, 2005).

Brazil has advanced in implementing the necessary support to the full and effective exercise of legal capacity by all persons with disabilities, to commit to the equalization of opportunities for that disability is not used as an impediment to the realization of dreams, desires and projects, valuing the role and the choices of Brazilians with and without disabilities (Deficiência, 2013).

In relation to the labor market and educational process, Mattos (2006), states that we should stress that the labor market policy and social integration requires a transformation in the practice of the policies and implies redefining the role of the teacher and the dynamics of relationships social in and out of the classroom. We totally abhor the idea that the responsibility for the integration process is only the specialist teacher, a stronghold called the classroom. Indeed, it is through the construction of an autonomous collective pedagogical project and facing the diversity that the integration proposal begins to resonate and to contextualize the different education systems (Mattos, 2006).

\section{Technologies and Methodologies}

\subsection{MOOCs}

With regard to the Brazilian educational panorama in EAD, the MOOCs represent a change in online learning processes, enhancing learning, collaboration and interaction, exchange of ideas, questions, sharing experiences and collective development among students.

The characteristics that make up the MOOCs are to be: open courses and enables scalability. On the first, it means that even students who are not regularly recorded on promoting institution can participate. However, we must remember that a limitation to the open is associated with the requirement of minimum skills by the participants, the digital literacy, as well as technological infrastructure with internet access and preferably with a quality broadband enabling navigation without a lot of frustration. About scalability, the course design is appropriate to meet exponential growth in enrollment, reaching hundreds of thousands of students participating in each course offering (Mota, Inamorato, 2012).

The idea of MOOCs is, in fact, preceded by the global movement of Open Educational Resources (OER), which has been gaining ground in national and international scene. REA, a term coined in the UNESCO event in 2002, are educational or research materials, including complete courses, learning objects, text, video, books and software available in any format or medium, which is in the public domain or that have a open license to use, allowing the reuse and adaptation by third parties (Mota, Inamorato, 2012).

The EAD evolved 90s going from very popular VLEs such as Moodle, Teleduc, Rooda, among others. In late 2011 the MOOCs arise. Massive Open Online Course (MOOC), is a type of Open Course developed through the use of AVAS and tools such as Web 2.0 and Social Networking. Present a new scenario for DL, as regards the transition logic for transmitting communication logic (interaction) between the various more user profiles. Have its pillars based on the democratization of access to educational content.

The MOOCs currently have a readily available supply in the American educational scene, the main exponents: Coursera, Udacity, EDX (Mcfedries, 2012)

The characteristics that make up the MOOCs are to be: open courses and allow scalability.

\subsection{Technological Environment}

In this paper, we are using a new environment, the Wikispaces. Wikispaces Classroom is a social writing platform for education. We make it incredibly easy to create a classroom workspace where you and your students 
can communicate and work on writing projects alone or in teams. Rich assessment tools give you the power to measure student contribution and engagement in real-time.

Wikispaces Classroom works great on modern browsers, tablets, and phones (Wikispaces, 2014). Figure 1 shows the Wikispaces Frontpage.

Wikispaces Classroom is free for teachers and students and has over 10 million registered teachers and students on the platform. Having a place to manage all the activity, resources, conversations, and projects in your classroom is essential for keeping students, and teachers, organizing and working together (Wikispaces, 2014).

Wikispaces Classroom gives you the features you need to get your classroom organized. Our philosophy is to make managing the day-to-day work of your classroom easy, and to let you bring in the best resources, content, and tools from around the Internet under one roof (Wikispaces, 2014).

\section{SolAssist Learning}

In this article we use the Wikispaces for offering a course that aims to the presentation and use of assistive technologies and the integration of people with disabilities in the labor market, aiming at the adaptation of jobs according to their need.

There are several available tencológicos resources for each type of disability and this course aims to present them to teachers working in vocational training so that they use these technological resources.

Figure 2 shows the initial screen of SolAssist Learning developed by Wikispaces.

The development methodology of this research is the organization of teaching and learning materials and preparation of the environment through the use of Wikispaces platform. Learning Objects were selected to assist in the development of content and make it more dynamic learning.

Figure 3 shows the organization of the Unit IV, which contains texts, learning objects and activities to be performed in the environment. The course was organized in 7 units containing TA on content.

Along with environmental preparation course participants were selected. The criteria for the selection of candidates were to be a teacher active in vocational education, working with people with disabilities and access technologies.

The course developed had the duranção 100 hours, and took place from September to December 2014. He obtained five modules, each of a different workload. 30 participants started the course of which 18 came through with active participation in the course.

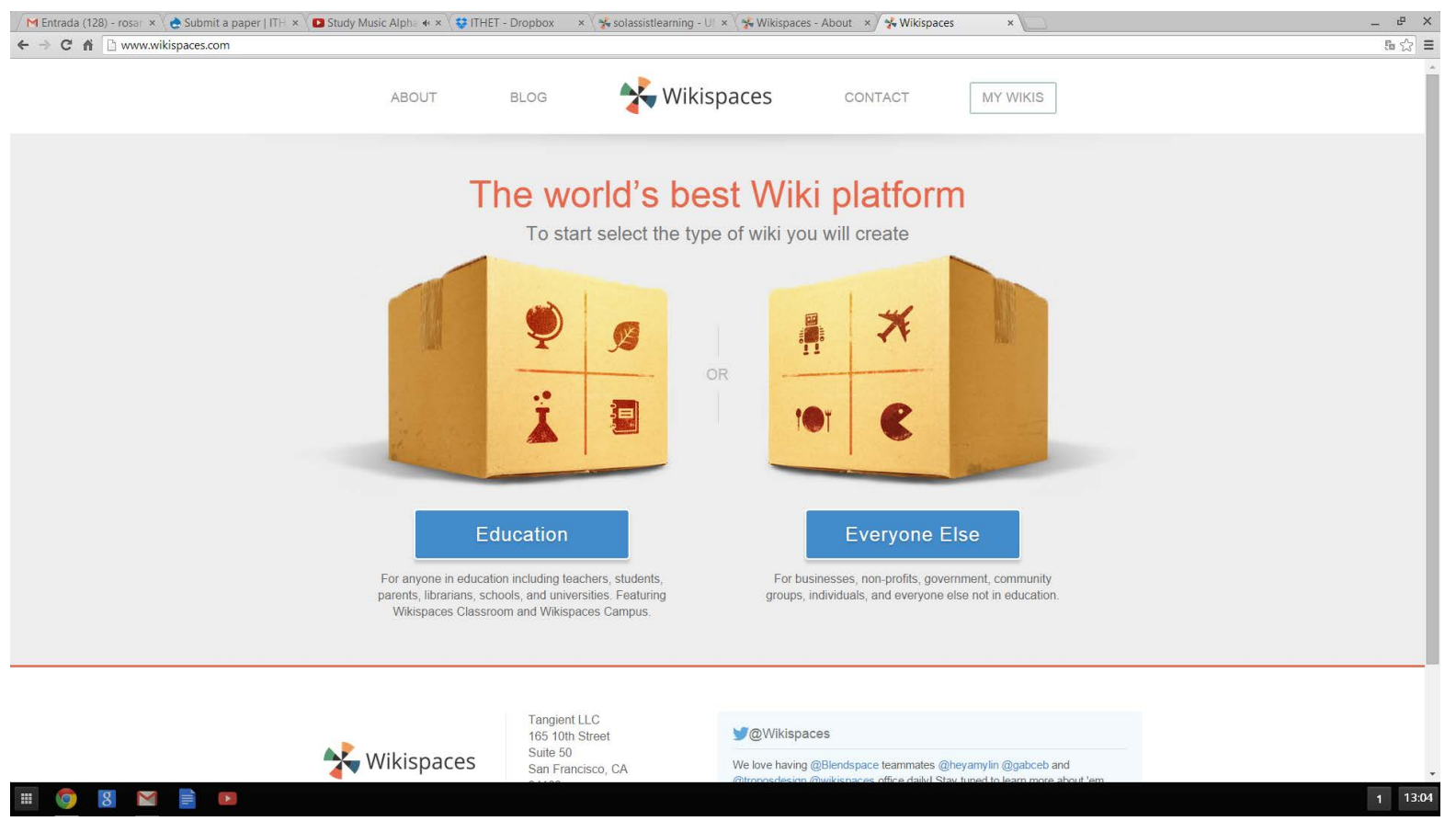

Figure 1. The Wikispaces FrontPage (Wikispaces, 2014). 


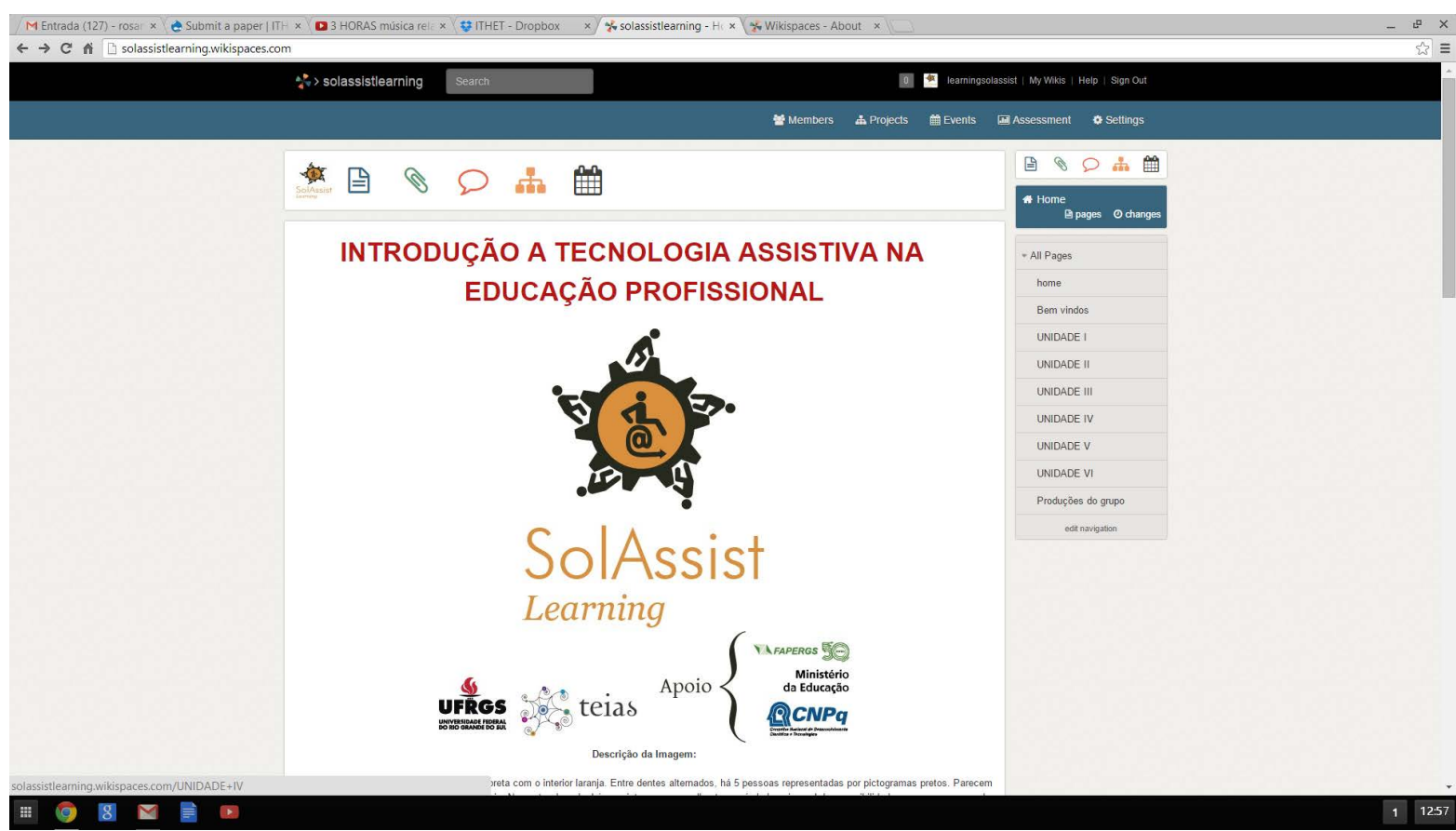

Figure 2. SolAssist Learning environment, using Wikispaces classroom.

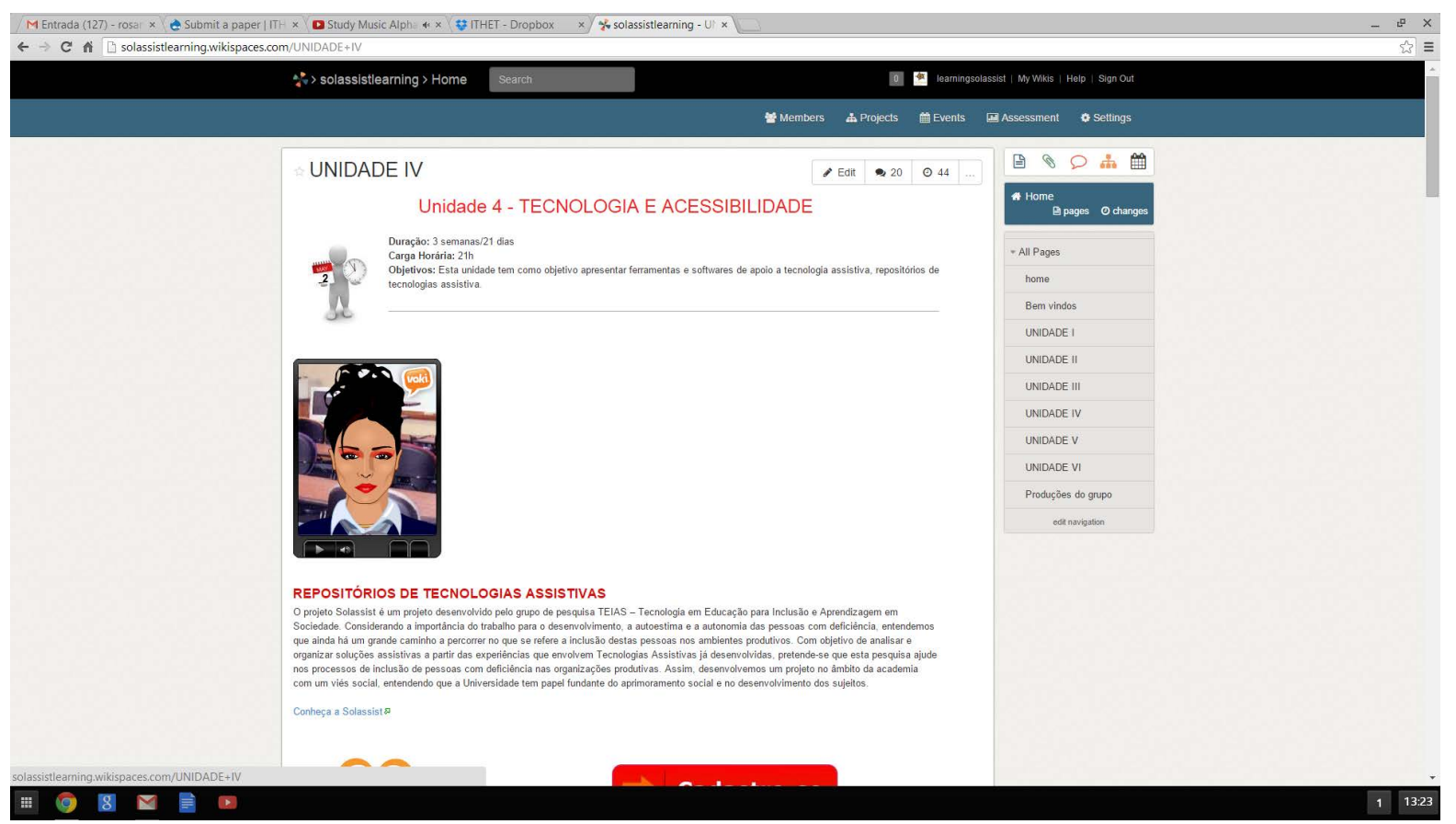

Figure 3. Unit IV of SolAssist Learning.

A number of assessment questionnaires were available and made it possible to obtain qualitative and quantitative data about the course developed.

For the course participants to interact and learn from each other, a flap was created "group productions", as shown in Figure 4, where issued to all links of personal pbworks, thus enabling everyone could view the contents of colleagues, thus making the most dynamic and complete learning through interaction among participants. 
Wikispaces is possible to restrict access in this way it was possible to check that all the information could only be accessed by own course participants and administrators, thereby maintaining the identity of preserved course participants.

\section{Results}

At the end of the course was applied another questionnaire, which made it possible to analyze the effectiveness of the course. All course participants worked, which made it a bit difficult the continuation of the whole group. A total of 35 persons were selected for the current realization. Some of these before accessing the course environment had already given up. Some course participants reported difficulty working with the technological tools used and the Wikispaces environment. By accessing the environment before being logged in the course you need to create a username and password and these instructions are in English. Some course participants reported significant difficulties with the foreign language. A total of 10 course participants finished the course with the time required for certification.

The graphs shown in Figures 5-8 represent data about the course and reports made by the course participants.

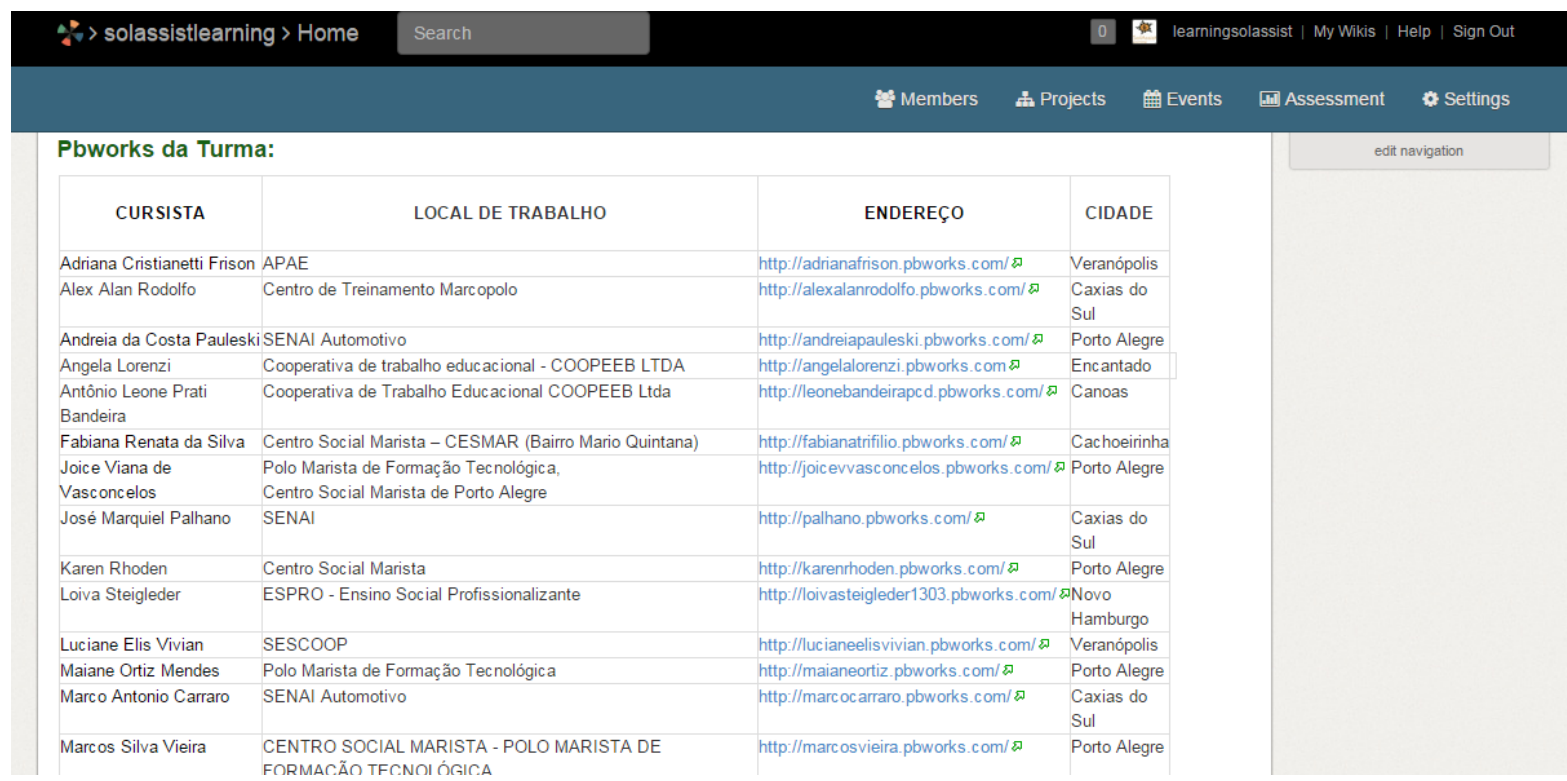

Figure 4. Tab "group productions”.

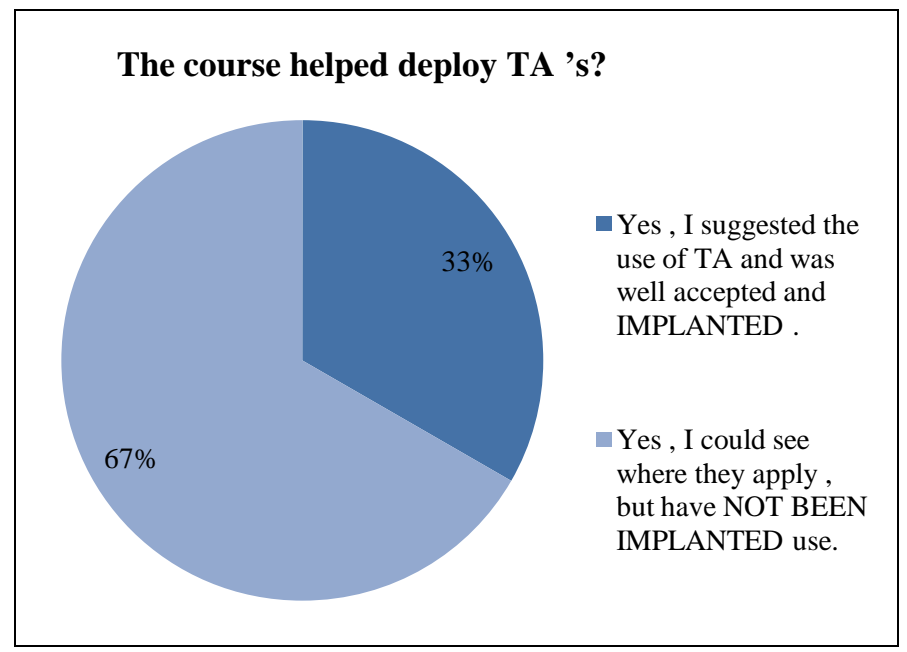

Figure 5. Course helped deploy TA. 


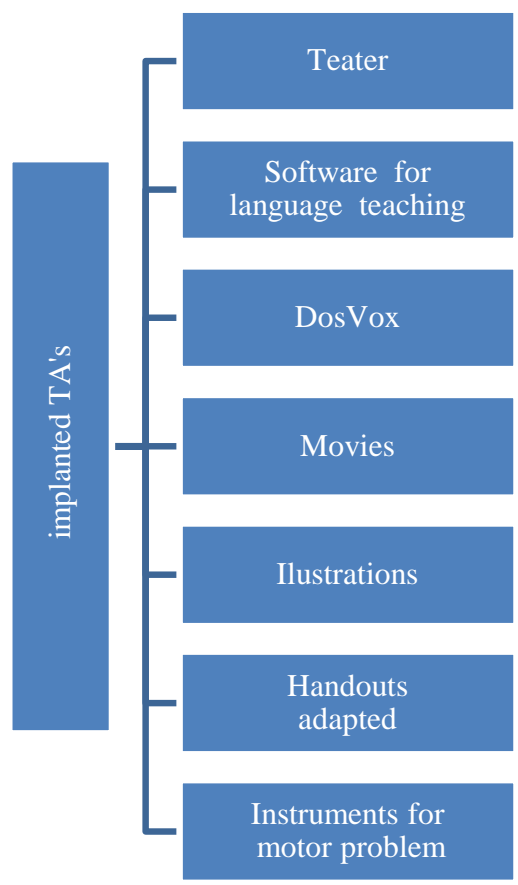

Figure 6. Implanted TA’s.

\section{Types of defects assisted by TA features}

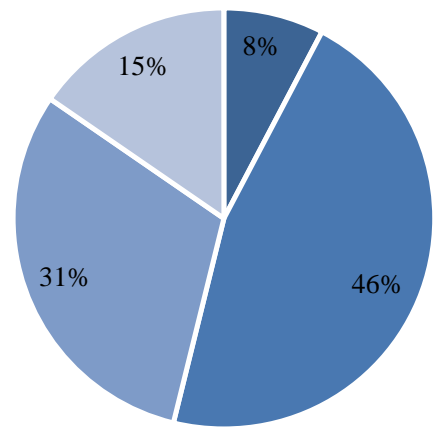

- Deficiêncy Hearing - Deficiêncy Visual

- Deficiêncy Physics - Outros

Figure 7. Defects assisted by TA.

Figure 5 shows the number of course participants who managed to successfully implement the use of Tas in working institution and Figure 6 shows what were the Assistive Technologies that could be used after the course participants have done the course.

Figure 7 shows the types of disabilities and resources that could be deployed by the course participants based on the knowledge acquired during the course and Figure 8 which Tas resources that were used.

\section{Conclusion}

Through noticeable expansion of Distance Education become necessary always new ways of using current technologies combined with this type of education. On this basis, this paper presents one of the researches being carried out by the research group on the development of new technologies combined with EAD and the concept of MOOCs. 


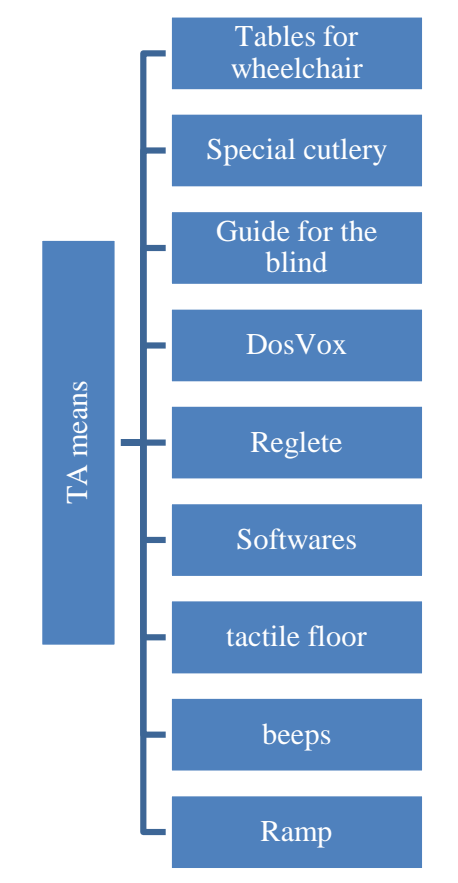

Figure 8. TA means.

Through the answers to the questions was possible to generate an overview of the target audience of the Course and their difficulties, and on the demands that have been presented in accordance with ambient adaptations needs work and alterations needed.

At this time, detailed analyzes are being made by using the software NVivo regarding participation in forums, allowing the analysis of other data that became evident during the participation of the course participants.

The completion of this pilot project makes possible to get an overview. For the project to be developed, using the data will be the key obtained so far in order to enable a more complete training to course participants.

Furthermore, others learning objects can be inserted in this context, and may eventually become important forms of the aid in the form of the vocational education.

At this time, and at the survey of quantitative data on the development of the course, new researches on environmental integration which develop Wikispaces with other technological tools are also being carried out, such as the use of virtual reality environments and VirtualTche that is developed in previous research.

\section{References}

Aprendiz Legal (2014). O Programa.

http://www.aprendizlegal.org.br/main.asp?TeamID=\{5E361F95-62FC-41FB-81F6-DEE27C2562B4\}

Brasil (2004). Legislação brasileira sobre pessoas portadoras de deficiência. Brasília: Câmara dos deputados, Coordenação de Publicações.

Deficiência (2013). Viver sem Limite-Plano Nacional dos Direitos da Pessoa com/Secretaria de Direitos Humanos da Presidência da República (SDH/PR)/Secretaria Nacional de Promoção dos Direitos da Pessoa com Deficiência (SNPD) • VIVER SEM LIMITE-Plano Nacional dos Direitos da Pessoa com Deficiência: SDH-PR/SNPD.

Machun, P. et al. (2012). MOOCs: Is There an App for That? IEEE/WIC/ACM International Conferences on Web Intelligence and Intelligent Agent Technology, 3, 321-326.

Mattos e. A. Deficiente Mental: Integração/Inclusão/Exclusão. (2006) São Paulo: Mandruvá.

http://www.hottopos.com/videtur13/edna.htm

Mcfedries, P. (2012). I'm in the Mood for MOOCs. IEEE Spectrum, 30.

Mota, Inamorato (2012). MOOC, uma revolução em curso. Jornal da Ciência. Publicado em 26/11/12.

Pronatec (2013). Objetivos e Iniciativas. http://pronatec.mec.gov.br/institucional/objetivos-e-iniciativas

Sassaki, R. K. (2005). Inclusão: Paradigma do Século 21. Revista da Educação Especial. Brasil: Ministério da Educação/Se- 
cretaria de Educação Especial.

Stiubiener, I. et al. (2011). Using Virtual Worlds in Distance Learning Environments. Frontiers in Education Conference (FIE), Rapid City, 12-15 October 2011, F3C-1-F3C-6. http://dx.doi.org/10.1109/fie.2011.6142822

Wikispaces (2014). http://www.Wikispaces.com/ 